\title{
Tactile Contact as a Marketing Tool for Improving an HIV/STD Education Program's Compliance / Retention with Crack Cocaine Users
}

\section{Ralph Jay Johnson}

Research Coordinator, University of Texas MD, Anderson Cancer Center; Chaplain Texas Medical Center Catholic Chaplaincy Corp, Texas

Corresponding Author: Ralph Jay Johnson, Research Coordinator, University of Texas MD, Anderson Cancer Center, Chaplain, Texas Medical Center Catholic Chaplaincy Corp, Texas.

Received Date: December 17, 2019; Accepted Date: January 17, 2020; Published Date; January $20,2020$.

Citation: Ralph Jay Johnson Tactile Contact as a Marketing Tool for Improving an HIV/STD Education Program's Compliance / Retention with Crack Cocaine Users, J. Psychology and Mental Health Care.4(1) Doi: 10.31579/2637-8892/067.

Copyright: ( ) 2020 Ralph Jay Johnson, This is an open-access article distributed under the terms of the Creative Commons Attribution License, which permits unrestricted use, distribution, and reproduction in any medium provided the original author and source are credited.

\section{Abstract}

Background: This research brief reports results from an exploratory pilot study on the use of socially acceptable touch in a public setting that accompanies a request to improve program compliance with "street level" crack cocaine users.

Methods: Study participants consisted of 120 crack cocaine-using participants in a larger community-based HIV/STD prevention and research program targeting at-risk African-Americans. They were required to return for a series of four booster health education sessions over 2-5 days and 6 month and 1 year follow-up assessments. The most difficult aspect of this program was no-shows for the second booster session; study participants who attended at least two sessions were much more likely to attend all sessions and complete the entire lengthy program. The program director randomly approached some participants after the first visit in a public setting and briefly touched them as part of a handshake; then, the director asked them to return for their follow-up sessions. Whether they were approached or not was random. Analysis comprised descriptive and non-parametric statistics.

Results: Ninety-three percent of participants who were asked to return and were touched returned for the second session; only $75 \%$ returned who had been asked to do so but were not touched. A statistically significant difference favored being touched and complying, as measured by second-session returning participants $(\mathrm{p}<.01)$, though it appeared the touch / request had more of a preventive than a promotional effect. Extraneous demographic and background factors were ruled out with the exception of age (older participants), which contributed slightly.

Conclusions: Results suggest that a request "anchored" to a socially acceptable public touch is promising in terms of improving program participation and engagement. Limitations and implications for future research are discussed.

Keywords: tactile contact; tactile stimulation; touching; program compliance; anchoring; marketing tool

\section{Introduction}

Keeping participants continuously engaged in programs can be a difficult aspect of treatment services at best.[1-7] Nevertheless; common sense dictates; and research has shown; that the longer participants actively participate in programs; the better their prognosis.[8-15] A challenging task is communicating to participants the importance of sticking with a program. [13; 16-19] One of the most primal modes of communication is touch: research shows that; along with a suggestion or request; touch has a synergistic effect on compliance.+

In a series of foundational experiments in a variety of natural settings (e.g.; medication non-compliance; product sales; solicitations for gifts or favors; or help; information; and even free rides and violations of prohibited behavior; etc.) over several years; Gueguen and associates[2025] convincingly demonstrated that a brief touch and a direct gaze accompanied by a request had a positive influence on compliancedespite the size of the request from the person doing the touching and whether recipients were even aware they were touched at all. Indeed; Hornik;[26] Smith; Gier; and Willis;[27] Willis and Hamm;[28] and Crusco and Wetzel [29] found that tactile contact enhanced spontaneous compliance and improved sales - even when no request was made.
Nevertheless; though a logical next step; few; if any; researchers have evaluated the practical and cost-effective use of touch accompanied by a direct gaze in requests to proactively encourage continued attendance of intervention programs in the interest of boosting retention - that is; as a program marketing tool. This is unusual given the number of marketing articles urging the "personal touch" to improve program attendance and compliance and customer/brand loyalty in general.[30-37] To test this effect; a pilot sub-study within a larger demonstration and research program was carried out. Participants in a community-based HIV/STD prevention project-who were currently using crack cocaine-were asked to return to a storefront outreach center after their initial visits for a series of four sequential daily "booster" sessions of health education over 4-5 days. Upon leaving the center; some participants were approached by the project/clinic director; who briefly touched them with a "supported" congratulatory handshake and; looking them directly in the eyes; asked that they return for their next scheduled visit.

The expectation was that those who were touched in this manner were more likely to comply than those who were not. Though the research question may not have been novel; its next logical extensionspecifically; practical application and programmatic evaluation - was unique and innovative; and constitute an advancement. The purpose of 
this research article is to briefly report the results of the exploratory pilot sub-study.

\section{Methods}

\section{Study Volunteers}

Seventy-five male and 45 female $(\mathrm{N}=120)++$ African American program participants served as study volunteers.

\section{Participants}

Study participants were part of a larger research project that compared different modes of health education to improve condom use and safe-sex practices among African Americans currently smoking crack cocaine and engaging in risky sex. Volunteers had been recruited to a storefront outreach center where they were given a baseline interview and an initial health education session. They were expected to attend four more daily "booster" sessions on four subsequent days. Then they were supposed to return for reevaluation six and 12 months later.

However; some simply did not return after the initial session despite remuneration incentives for each attendance and repeated attempts to recontact and encourage them to return. The daunting challenge was motivating participants; who were substantially unreliable; transient; and itinerant; to return the next day for their second session. ${ }^{\text {cf.2 }}$ Excluded from this marketing pilot study were those who failed to return because of a verified and documented extraneous event or factor (e.g.; arrest and longterm incarceration; permanent relocation; hiding and on the run; death; or extended in-patient drug treatment).

\begin{tabular}{|c|c|c|c|c|c|c|c|c|}
\hline \multirow[b]{2}{*}{ Gender } & & & \multicolumn{6}{|c|}{$N=120$} \\
\hline & & & Not Touched & & & Touched & Total & \\
\hline & Male & 39 & $32 \%$ & & 36 & $30 \%$ & 75 & $62 \%$ \\
\hline & Female & 21 & $18 \%$ & & 24 & $20 \%$ & 45 & $38 \%$ \\
\hline $\begin{array}{l}\text { Age (years } \\
\text { old)* }\end{array}$ & & & $\begin{array}{c}\text { Mean }=33 \\
\text { Range }=18-40 \\
\text { Std }=6\end{array}$ & & & $\begin{array}{c}\text { Mean }=34 \\
\text { Range }=19-40 \\
\text { Std }=6\end{array}$ & & $\begin{array}{c}\text { Mean }=34 \\
\text { Range }=18-40 \\
\text { Std }=6\end{array}$ \\
\hline \multicolumn{9}{|l|}{$\begin{array}{c}\text { Monthly } \\
\text { Income** }\end{array}$} \\
\hline & $\$ 600>$ & & 20 & $16 \%$ & 17 & $14 \%$ & 37 & $30 \%$ \\
\hline & $\$ 100-\$ 500$ & & 30 & $25 \%$ & 33 & $27 \%$ & 63 & $52 \%$ \\
\hline & $\$ 0-\$ 100$ & & 8 & $7 \%$ & 9 & $8 \%$ & 17 & $15 \%$ \\
\hline & Missing & & 2 & $2 \%$ & 1 & $1 \%$ & 3 & $3 \%$ \\
\hline $\begin{array}{l}\text { Years in } \\
\text { School }\end{array}$ & & & $\begin{array}{c}\text { Mean }=13 \\
\text { Range }=7-16 \\
\text { Std }=2\end{array}$ & & & $\begin{array}{c}\text { Mean }=12 \\
\text { Range }=7-18 \\
\text { Std }=2\end{array}$ & & $\begin{aligned} \text { Mean } & =12 \\
\text { Range } & =7-18 \\
\text { Std } & =2\end{aligned}$ \\
\hline \multicolumn{9}{|l|}{ Housing } \\
\hline & $\underset{* * *}{\text { Permanent }}$ & 11 & $11 \%$ & & 15 & $12 \%$ & 28 & $23 \%$ \\
\hline & $\underset{* * * *}{\text { Transitory }}$ & 37 & $37 \%$ & & 42 & $35 \%$ & 87 & $72 \%$ \\
\hline & Streets & 1 & $1 \%$ & & 1 & $1 \%$ & 2 & $2 \%$ \\
\hline & Missing & 1 & $1 \%$ & & 2 & $2 \%$ & 3 & $3 \%$ \\
\hline
\end{tabular}

\section{Table I: Tactile Study Participants' Demographic and SES Profile}

*The max upper age for entrance into the main study was 40 years old.

**Surprisingly; for street level drug users; $34 \%$ received income from some kind of full or part-time job; though the exact nature of their work was unknown. Fifty-four percent received income for "alternative" sources; including: unemployment benefits; VA/SSI disability; public assistance; spouse/sex partner; family; friends; trading sex for money; illegal sources; and "odd jobs."

***Permanent Housing included a house or apartment for which the Study Participant was responsible.

****Transitory Housing was someone else's house/apartment; hotels; rooming/boarding houses; dormitories; half-way houses; jail; or a shelter. "Streets" included homeless on the streets and vacant buildings. 
Table I provides a demographic and Social-Economic-Status (SES) profile of the study participants in order to assess whether there were significant differences between the Touched and Not Touched groups that could influence subsequent return rates. Generally; the two groups were homogenous. Nevertheless; there were slight differences between them. It should be noted that selection into either group was random and not based on these criteria. Thus; there was no way to know how the two groups fared regarding these criteria; or even their return rates; until nearing the study's end. In this sense; the study was "blinded."

Also; given how study participants were included; it would have been nearly impossible to achieve a perfect match; although the similarity of the two groups was remarkable. Table I reveals that the differences in terms of demographics and SES were slight; if not inconsequential. More of the Touched group were females (4\%); lived in permanent housing (1\%); and were older; but were slightly less educated and with less income (2\%). Whereas; the Not Touched group somewhat represented a very mild anti-thesis: more Male (2\%); more living in transitory housing (2\%); they were younger; and they had slightly less education; but had more income (2\%). Remarkably; for street level crack cocaine users; many program participants had at least a GED (high-school equivalency exam certificate); if not a high school diploma and some college (usually a couple of years of community college).

\section{Procedure}

As part of normal office protocol; the "script" consisted of; after participants' initial session and when they were leaving the center (see Digital Picture); of the following:

(1) The project/clinic director would catch them at or outside the office door; (2) introduce himself; (3) extend a hand to offer a congratulatory handshake on "completing the first session"; (4) if the person extended his or her hand back and shook the director's hand; (5) the director would use his other hand to steady the handshake by touching the person's hand/forearm; (6) then the director would look directly into the person's eyes and (7) request that the person come back for the next session. (Naturally; the project/clinic director did practice hand hygiene between encounters to reduce the risk of hand-borne infectious disease transmission.)

\section{Digital Picture of Intervention}

Note: Though visual facial features in the photo were redacted or concealed; informed consent included permission for visual recording followed/supported by verbal assent for both parties.

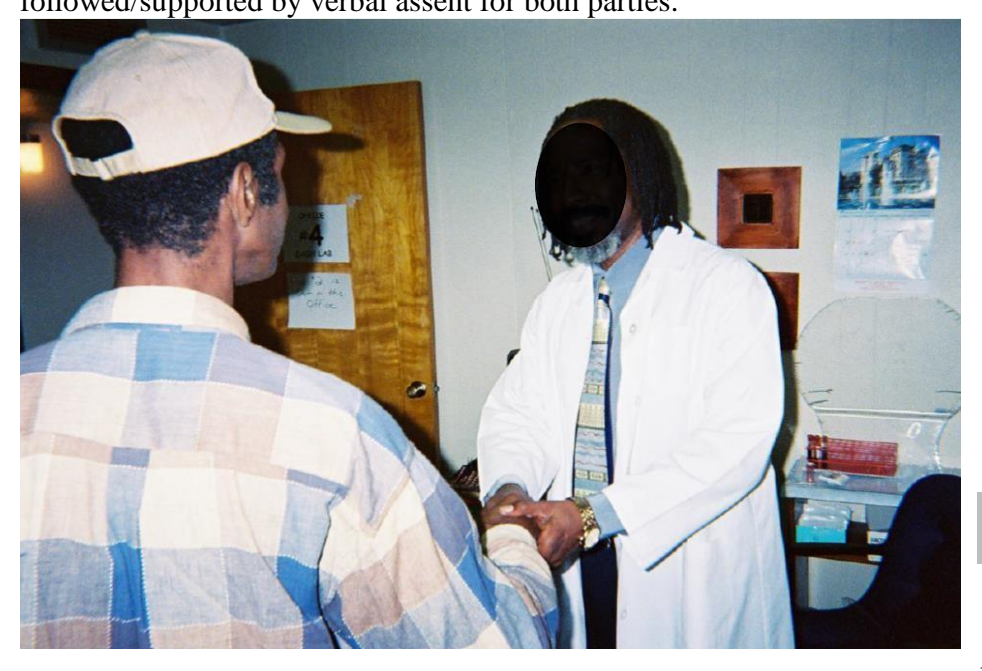

An attractive feature of this procedure as a program marketing tool is that it involved ordinary; polite public behavior that did not violate social norms; was not offensive; and occurred with participants' permission. The hope was that this would help improve return rates for the second session; and ideally; once the participants got into the habit of returning; overall retention rates for the three remaining sessions would improve; as would the subsequent 6- and 12-month return rates for re-evaluation visits. One of the measures of the program's success was Continuity of Care. The assumption was that; if the program could encourage this rather difficult; intransient; and intractable target population to return multiple times to attend "booster" follow-up health education and risk reduction sessions; then that increased the possibility they would retain the instructional material over time. ${ }^{\text {cf. }}[\mathbf{7} ; \mathbf{9 ;} ; \mathbf{1 0} ; \mathbf{1 2}]$

Nevertheless; the project director could not reach everyone. By default; some participants met the director and received the touching and request while others did not; which was documented. Whether or not a client received the touching and request was random. Prior to their program enrollment; informed consent was obtained from all participants; and those who were touched were given the opportunity to debrief regarding this particular study. Only three requested the debriefing.

The study was reviewed and approved by the University of TexasSchool of Public Health Human Subjects Protections Committee and adequate informed consent to participate was obtained from study participants.

Data Collection and Analysis: Assignment to the Touched and Not Touched groups was noted in the study participants' program files; which also included their progress through the program's sessions. Study participants were recruited until 60 was reached for each group. Data were entered electronically and analysis consisted of using descriptive statistics and a Chi-Square and Odds Ratio. In accordance with the nominal outcome measure; binomial multiple logistic regression was employed as a postscript to examine possible explanatory influence of extraneous cofactors.

\section{Results}

Analysis showed that 93\% (56 of 60) of the participants who had been touched returned for a second session as opposed to $75 \%$ (45 of 60 ) who had not been touched. The most dramatic results were among those who did not return: $80 \%$ (15 out of 19 ) had not been touched while $20 \%$ (4 out of 19) had been touched.

\begin{tabular}{|l|l|c|c|c|}
\hline & & $\begin{array}{c}\text { Not } \\
\text { Touched }\end{array}$ & Touched & \\
\hline Return for Session 2 & No & $15(13 \%)$ & $4(3 \%)$ & $19(16 \%)$ \\
\hline Return for Session 2 & Yes & $45(37 \%)$ & $56(47 \%)$ & $101(84 \%)$ \\
\hline Odd Ratio $=4.667$ & & $60(50 \%)$ & $60(50 \%)$ & 120 \\
CI $=1.447-15.046$ & & & & \\
\hline
\end{tabular}

Table II: Chi-Square/Odds Ratio Second-Session Return for Touched vs. Not Touched

The difference between the rates was significant $\left[X_{1}^{2}(\mathrm{~N}=120)=7.567\right.$; $p<.01]$. There were no significant differences between demographic and 
background variables except for age. Seventy percent of the older participants (older than 30 ) returned while only about $15 \%$ of the younger ones $(18-30$ years old $)$ returned $\left[X_{1}^{2}(\mathrm{~N}=120)=7.22 ; p<.01\right]$. Logistic regression revealed that touching $(B=1.557 ; p=.01)$ appeared to positively affect rates of returning for the second session; and age $(B=$ $.116 ; p<.03$ ) only contributed slightly though its effect could not be ruled out. Overall; 90 participants who attended their second session also attended their subsequent three sessions and their 6- (90\%) and 81 of those $(81 \%)$ their re-evaluations. So; theoretically a touched participant would have a 5 times greater chance of returning for their second session and completing the entire intervention.

\section{Conclusions}

The study's results support the contentions of previous researchers ${ }^{25-29}$; but extended them through practical application. Specifically; socially acceptable public touch had a significant effect on program compliance / retention when anchored to a request for the participants; defined here as coming back for a return visit. The most dramatic difference was between those who were not touched and failed to return (21\% vs. $79 \%)$ as opposed to those who were not touched and returned (45\% vs. 50\%). Apparently; the touching had a preventive rather than a promoting effect. Nevertheless; these results support a practical; efficient; and costeffective application of combining socially acceptable touching with a request or instruction to boost compliance for a population known to be particularly difficult in terms of program participation and compliance.[38-40] The potential adaptations of this simple technique are unlimited for improving retention in programs that involve participants' repeated involvement over time. The technique is not harmful or impolite and allows for a demonstration of genuine interest and even appreciation toward participants' continued engagement with a program.

\section{Limitations}

The findings were not without limitations. First; the project/clinic director was male. Future research should examine whether gender or a status makes a significant difference in the return rate. Second; little is known

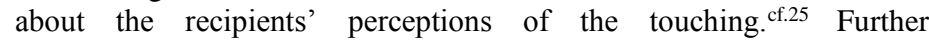
investigations should consider whether and how (1) the effects of touch are mediated through the recipients' positive perceptions; (2) the awareness of being touched makes a difference; and (3) what being touched means to recipients.

Third; compliance was measured only in terms of returning for the second visit. Further inquiry might look into whether touch and a request improve compliance with other types of requests; other populations; and other program settings. Fourth; the population represented one ethnicity in one city; and one programmatic target population. Future research should investigate cultural differences in terms of the social appropriateness and influence of touching accompanied by a request in different settings.

Fifth; the relevance of age should be appraised more carefully; as should possible other unknown extraneous mediating factors. Sixth; the confidence intervals for the Odd Ratio; though statistically significant; were relatively substantial. This is probably due to the study being low statistically powered (but not underpowered) - hence further; larger; and more inclusive studies are suggested. This also would accommodate expanded analysis.

Finally; critics might argue that this study was merely reaffirmation of desirability bias at work in research. That is; the participants were doing nothing more than responding to research cues (e.g.; the Hawthorne effect+++ revisited). However; the original intent of the study was to pilot test a socially acceptable and easy-to-use cue for managers and researchers to use to improve program compliance and retention; with less regard for the underlying mechanisms that make the behavior effective.

Despite its shortcomings; the study strongly supports the positive and promising effects of the practical deployment of benign touch in a brief public encounter on improving compliance with a request-even a relatively substantial request-in a program or clinic setting. Additionally; compliance with such an initial request has the possibility of increasing further compliance. Hopefully; limitations in light of the dated information in the literature; the results reported herein will stimulate new research to foster and refine what is known about uses of tactile contact and compliance.

+Hypnotherapists have long understood the "anchoring" power of touch accompanied by suggestion in that touch focuses attention to the area touched; thereby altering the state of consciousness and making one more open to suggestion. $[\mathbf{1 5 ; 1 8}]$ In their common parlance; hypnotherapists refer to this procedure as "dropping an anchor" on someone. Note: No study participants were hypnotized; that was not the aim of the study. (https://www.mindtosucceed.com/self-hypnosis-techniques.html https://www.braindirector.com/how-to-use-anchors-in-hypnosis-and- nlpfor-building-confidence/)

++ A statistical power test revealed that the sample size provided $95 \%$ power to detect statistically significant differences at a $<.05$ alpha acceptance level.

+++ Two researchers studied working conditions at the Hawthorne Western Electric Works in Chicago to discover what conditions would improve employee satisfaction and productivity. They found that just about every adjustment; good or bad; improved satisfaction and productivity - until they realized that the improvements were more a function of the experiments themselves and the presence of the experimenters. $[\mathbf{4 1 ; 4 2 ]}$

\section{Declarations}

\section{Funding}

This project was supported by a grant from the National Institute on Drug Abuse to the University of Texas-Houston School of Public Health RO3 DA12328. The author gratefully acknowledges UT-MDACC for in-kind support.

\section{Compliance with Ethical Standards}

The author has no conflict of interest to report related to the study.

\section{Ethical Approval}

The study was approved by the University of Texas-HRC-SPH Human Subjects Committee and adequate informed consent to participate was obtained from Study Participants.

\section{Data Repository}

Requests for reprints and other inquiries should be addressed to Ralph $\mathbf{J}$ Johnson at the University of Texas MDACC, Dept. of Myeloma, Unit 429, 1515 Holcombe Blvd., Houston, TX, 77030, USA; or rjjohnson@mdanderson.org.

\section{Acknowledgements:}

The opinions expressed herein are those of the author. The author would 
like to thank Drs. M.L. Williams; M.W. Ross; and S. Timpson for proof of concept and critical reviews; and also Dr. J Atkinson for moral support. The Author also thanks Ms. Jacqueline Ramey and Ms. Aileen "Acey" Cho freelance copy-editors for proofing and copyediting.

\section{References}

1. Veniegas RC; Kao UH; Rosales R; and Arellanes M; (2009). HIV prevention technology transfer: Challenges and strategies in the real world. Research and Practice: AJPH. 2009;99:S124S130. doi:10.2105/AJPH.2007.124263

2. SAMSHA/CSAT; (2006). Clinical issues; challenges; and strategies in intensive outpatient treatment (Chapter 7) in Substance Abuse: Clinical Issues in Intensive Outpatient Treatment: Treatment Improvement Protocol (TIP) Series; No. 47. Center for Substance Abuse Treatment. Rockville; MD: Substance Abuse and Mental Health Services Administration (US); Report No. (SMA) 06-4182.

3. Wisdom JP; Hoffman K; Rechberger E; Seim K; et al.; (2009). Women-focused treatment agencies and process improvement: Strategies to increase client engagement. Women \& Therapy; 32:69-87.

4. Swift JK; Greenberg RP; Tompkins KA; and Parkin SR; (2017). Treatment refusal and premature termination in psychotherapy; pharmacotherapy; and their combination: A meta-analysis of head-to-head comparisons. Psychotherapy (Chic). 2017 Mar;54(1):47-57. doi: 10.1037/pst0000104.

5. Swift JK and Greenberg RP. (2012). Premature discontinuation in adult psychotherapy: A meta-analysis. J Consult Clin Psychol. 2012 Aug;80(4):547-59. doi: 10.1037/a0028226. Epub 2012 Apr 16. https://psycnet.apa.org/record/2012-10020-001

6. Van Loggerenberg F; Mlisana K; Williamson C; Auld SC; et al.; (2008). Establishing a cohort at high risk of HIV infection in South Africa: Challenges and experiences of the CAPRISA 002 acute infection study. PLOS One; April 16. 2008.

7. Calsyn RJ; Klinkenberg WD; Morse GA; Miller J; et al. (2004). Recruitment; engagement; and retention of people living with HIV and co-occurring mental health and substance use disorders. Journal AIDS Care Psychological and Socio-medical Aspects of AIDS/HIV Volume 16; 2004 - Issue sup1; S56-70.

8. Morgenstern H; Gellert GA; Walter SD; Ostfeld AM; et al.; (1984). The impact of a psychosocial support program on survival with breast cancer: The importance of selection bias in program evaluation. Journal of Chronic Disease; 37; 4; 273-282.

9. Zhu LX; Ho SC; Sit JW; and He HG. (2014). The effects of a transtheoretical model-based exercise stage-matched intervention on exercise behavior in patients with coronary heart disease: A randomized controlled trial. Patient Educ Couns. 2014 Jun;95(3):384-92. doi: 10.1016/j.pec.2014.03.013. Epub 2014 Mar 29.

10. DiClemente CC; Delahanty JC; Kofeldt MG; Dixon L; et al.; (2011). Stage movement following a 5A's intervention in tobacco dependent individuals with serious mental illness (SMI). Addict Behav. 2011 Mar;36(3):261-4. doi: 10.1016/j.addbeh.2010.11.002. Epub 2010 Nov 19.

11. McHugo GJ; Drake RE; Teague GB; and Xie H; (1999). Fidelity to assertive community treatment and client outcomes in the New Hampshire dual disorders study. Psychiatric Services; 50; 6; 818824 .

12. Schumann A; Stein JA; Ullman JB; John U; et al. 2008.Patterns and predictors of change in a smoking intervention study: Latent growth analysis of a multivariate outcome model. Health Psychol. 2008 May; 27(3S):S233-42.

13. Joe GW; Simpson DD; Dansereau DF; and Rowan-Szal G; (2001). Relationship between counseling rapport and drug abuse treatment outcomes. Psychiatric Services; 52; 9; 1223-1229.

14. Sherril JT; Frank E; Geary M; Stack JA; and Reynolds CF III; (1997). Psychoeducational workshops for elderly patients with recurrent major depression and their families. Psychiatric Services; 48; 1; 76-81.

15. cf. Fawcett J; (1995). Compliance: Definitions and key issues. Journal of Clinical Psychiatry; 56 (suppl. 1); 4-8. PMID: 7836349

16. Velicer WF; Norman GJ; Fava JL; and Prochaska JO. (1999). Testing 40 predictions from the transtheoretical model. Addict Behav. 1999 Jul-Aug;24(4):455-69.

17. Parashar S; Palmer AK; O'Brien N; Chan K; et al.; (2011). Sticking to it: The effect of maximally assisted therapy on antiretroviral treatment adherence among individuals living with HIV who are unstably housed. AIDS Behav. 2011 Nov;15(8):1612-22. doi: 10.1007/s10461-011-0026-8.

18. Levitan AA and Johnson JM; (1986). The role of touch in healing and hypnotherapy. American Journal of Clinical Hypnosis; 28; 4; 218-223.

19. Donatone B; (2013). Focused suggestion with somatic anchoring technique: Rapid self-hypnosis for pain management. Am J Clin Hypn. Apr;55(4):325-42.

20. Gueguen N; (2002). Touch; awareness of touch; and compliance with a request. Perceptual and Motor Skills; 95; 355-360. https://psycnet.apa.org/record/2002-08352-003

21. Gueguen N and Fischer-Lokou J; (2003). Tactile contact and spontaneous help: An evaluation in a natural setting. Journal of Social Psychology; 143(6); 785-787. PMID: 14658752 DOI: 10.1080/00224540309600431.

22. Gueguen N and Fischer-Lokou J; (2003). Another evaluation of touch and helping behavior. Psychological Reports; 92; 62-64.

23. Gueguen N and Fischer-Lokou J; (2002). An evaluation of touch on a large request: A field setting. Psychological Reports; 90; 267-269.

24. Gueguen N and Jacob C; (2002). Direct look versus evasive glance and compliance with a request. Journal of Social Psychology; 142 (3); 393-396.

25. Joule JV and Guegen N; (2007). Touch; compliance; and awareness of tactile contact. Percept Mot Skills: Apr; 104(2):581-8

https://journals.sagepub.com/doi/abs/10.2466/pms.104.2.581588

26. Hornik J; (1992). Effects of physical contact on customers' shopping time and behavior. Marketing Letters; 3; 49-55.

27. Smith D; Gier J; and Willis F; (1982). Interpersonal touch and compliance with a marketing request. Basic and Applied Social Psychology; 126; 141-142.

28. Willis FN and Hamm HK; (1980). The use of interpersonal touch in securing compliance. Journal of Nonverbal Behavior; 5(1);4955.

29. Crusco; AH and Wetzel; CG; (1984). The Midas touch: The effects of interpersonal touch on restaurant tipping. Personality and Social Psychology Bulletin; 10(4); 512-517.

30. Riesch SK; Ngui EM; Ehlert C; Miller MK; et al.; (2013). Community outreach and engagement strategies from the Wisconsin Study Center of the National Children's Study. Public 
Health Nurs. 2013 May;30(3):254-65. doi: 10.1111/phn.12018. Epub 2013 Jan 29.

31. Cohen J; (1997). Medicine: Developing prescriptions with a personal touch. Science 07 Feb 1997: Vol. 275; Issue 5301; pp. 776DOI: $10.1126 /$ science.275.5301.776

32. Zablocki E; (1997). A personal touch: When it comes to serving Medicare members; high touch approach pays off. Healthplan; 38 (5); 32-4 and 38-41. PMID: 10182879

33. Jaklevic MC. Walking seniors through first HMO takes a personal touch. Mod Healthc. 1995 Jun 19;25 (25):152; 154. PMID: 10143073

34. Manji I. (1993). Quality service and a personal touch: Redefining the "M" word. J Can Dent Assoc. Feb;59 (2):115-6. PMID: 8453513

35. Som A; 2005. Personal touch that built an empire of style and luxury. European Business Forum; Vol. 20; pp. 69-71.

36. Public Sector Contract Reports; (1997). Medicaid member retention begins at enrollment with plan; provider personal touch; 3 (8); 117-20.
37. Executive Solutions in Healthcare Management; (2000). A personal touch curbs Medicare HMO disenrollment; 3(3); 7-9.

38. Ompad DC; Giobazolia TT; Barton SC; Halkitis SN; et al.; (2016). Drug use among HIV+ adults aged 50 and older: Findings from the GOLD II study. AIDS Care. Nov;28(11):1373-7. doi: 10.1080/09540121.2016.1178704. Epub 2016 May 4.

39. Robles RR; Marrero CA; Matos TD; Colón HM; et al.; (1998). Factors associated with changes in sex behaviour among drug users in Puerto Rico. AIDS Care. Jun;10(3):329-38.

40. Hoffman JA; Caudill BD; Koman JJ III; Luckey JW; et al.; (1994). Comparative cocaine abuse treatment strategies: Enhancing client retention and treatment exposure. J Addict Dis. 1994;13(4):115-28.

41. "Hawthorne Effect": What Is Hawthorne Effect? - MBA Learner." MBA Learner. 2018-02-22.

42. Landsberger; HA; Hawthorne Revisited; Ithaca; 1958. Management and the worker: its critics; and developments in human relations in industry.

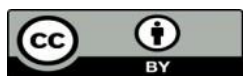

This work is licensed under Creative Commons Attribution 4.0 License

To Submit Your Article Click Here: Submit Article

DOI: $10.31579 / 2637-8892 / 067$
Ready to submit your research? Choose Auctores and benefit from:

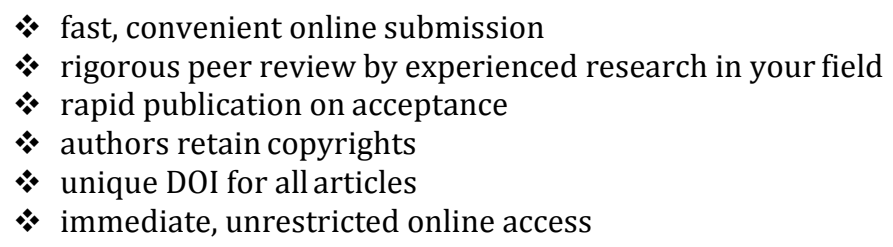

At Auctores, research is always in progress.

Learn more www.auctoresonline.org/journals/psychology-andmental-health-care 